\title{
Unilateral Naevoid Telangiectasia Associated with Oral Contraceptive
}

Takuma NOHARA ${ }^{1}$, Ken NATSUGA ${ }^{1 *}$, Atsushi YASUOKA ${ }^{2}$ and Hideyuki UJIIE ${ }^{1}$

${ }^{1}$ Department of Dermatology, Faculty of Medicine and Graduate School of Medicine, Hokkaido University, North 15 West 7, Sapporo 0608638 and ${ }^{2}$ Yasuoka Dermatology Clinic, Sapporo, Japan. *E-mail: natsuga@med.hokudai.ac.jp

Accepted Oct 26, 2021; Epub ahead of print Oct 26, 2021

Unilateral naevoid telangiectasia (UNT) is a rare congenital or acquired disorder characterized by segmental cutaneous telangiectasia. The acquired form is often associated with underlying conditions, such as pregnancy or liver disorders (1). We report here a female patient who developed UNT during administration of an oral contraceptive, but whose UNT ameliorated after the drug was withdrawn.

\section{CASE REPORT}

A 19-year-old woman presented with erythematous eruptions on the left forehead and upper eyelid (Fig. 1A). The lesion had appeared one year after she started drospirenone-ethinylestradiol oral contraceptive for irregular menstruation, and it had persisted for one year. The patient reported no history of alcohol intake or any other medical complications, including liver disease. Examination found the eruptions to be asymptomatic, non-palpable telangiectatic macules that faded with pressure. Dermoscopy showed numerous tortuous vessels on a whitish background (Fig. 1B). The biopsy specimen revealed capillary dilatation in the papillary and reticular dermis. Based on these findings, a diagnosis of UNT was made. The contraceptive was discontinued because it was suspected of triggering the lesions. However, because the patient's irregular menstruation recurred, norgestrel-ethinylestradiol was administered and then switched to dydrogesterone. The oral contraceptives were eventually withdrawn after her menstrual cycle normalized. Two months after contraceptive cessation, the patient's eruptions were significantly improved (Fig. 1C). No flare-ups were noted after 4 months.

\section{DISCUSSION}

High oestrogenic conditions have been implicated in the pathogenesis of UNT that develops during pregnancy or puberty (2). However, cases associated with oral contraceptives are extremely rare. A previous case series showed 2 cases of UNT that reacted differently from contraceptive agents (2). One patient with irregular menstruation showed improvement of a UNT lesion with the administration of oral contraceptives, while the other noted a worsening of a UNT eruption by contraceptives (2). The current case strongly suggests the involvement of the oral contraceptive in UNT development, because the lesions started after administration of drug and disappeared after withdrawal. Persistent, but not intermittent, exposure to certain levels of oestrogen might be essential for inducing the lesion, because no eruption was observed during normal menstruation in the patient. The current case also highlights that UNT can be reversed when the causes are eliminated. The clinical course of the current case is consistent with the improvement in pregnancyrelated UNT after delivery (3).

A previous study reported that the expression of oestrogen and progesterone receptors is upregulated in UNT sections (4), although this result has not reproduced (5). The Blaschkoid location of UNT suggests an association with cutaneous mosaicism (6), but this hypothesis remains speculative. Further studies are warranted to elucidate the UNT pathomechanism.
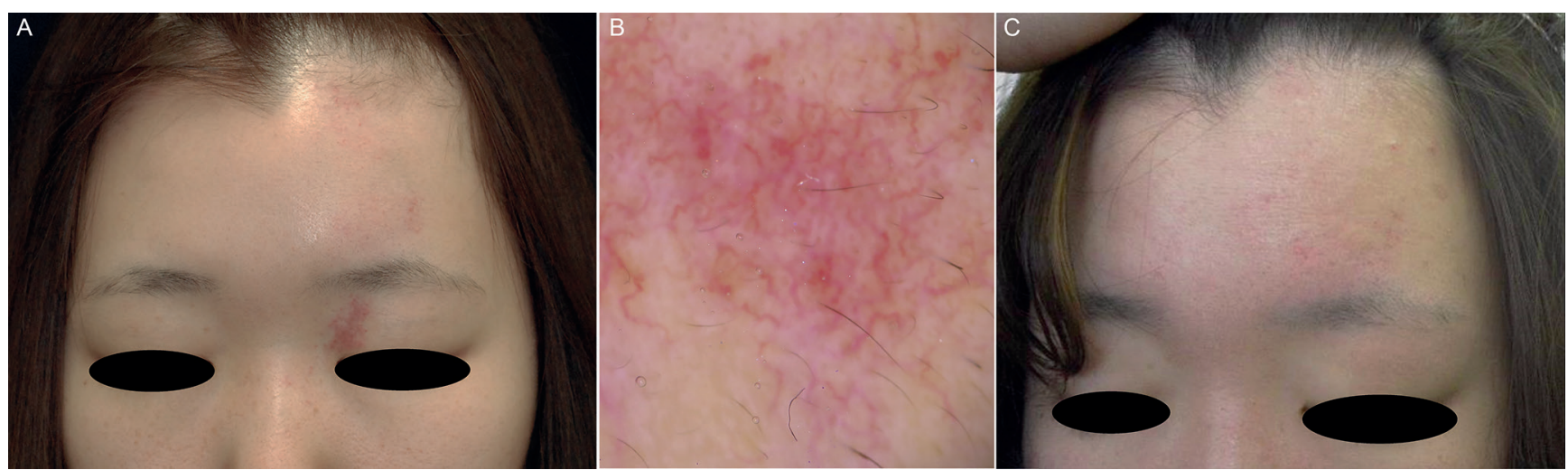

Fig. 1. Clinical manifestations and dermoscopic findings. (A) A telangiectatic macule on the left forehead and upper eyelid. (B) Tortuous vessels on a whitish background on dermoscopy. (C) The improved skin lesion 2 months after contraceptive withdrawal. 
In sum, this case strengthens the evidence for the role of oral contraceptives in the pathogenesis of UNT. Investigations into the conditions underlying UNT could avoid unnecessary interventions, such as laser treatment.

The authors have no conflicts of interest to declare.

\section{REFERENCES}

1. Tanglertsampan C, Chanthothai J, Phichawong T. Unilateral nevoid telangiectasia: case report and proposal for new classification system. Int J Dermatol 2013; 52: 608-610.

2. Wilkin JK, Smith JG Jr, Cullison DA, Peters GE, Rodriquez-
Rigau LJ, Feucht CL. Unilateral dermatomal superficial telangiectasia. Nine new cases and a review of unilateral dermatomal superficial telangiectasia. J Am Acad Dermatol 1983; 8: 468-477.

3. Michelerio A, Rivetti N, Bolcato V, Croci GA, Brazzelli V. Unilateral nevoid telangiectasia: a condition unmasked by hyperoestrogenism? Eur J Dermatol 2017; 27: 439-441.

4. Uhlin SR, McCarty KS Jr. Unilateral nevoid telangiectatic syndrome. The role of estrogen and progesterone receptors. Arch Dermatol 1983; 119: 226-228.

5. Wenson SF, Jan F, Sepehr A. Unilateral nevoid telangiectasia syndrome: a case report and review of the literature. Dermatol Online J 2011; 17: 2.

6. Hynes LR, Shenefelt PD. Unilateral nevoid telangiectasia: occurrence in two patients with hepatitis C. J Am Acad Dermatol 1997; 36: 819-822. 